\title{
Bidirectional Current Sensorless Control for the Full-Bridge AC/DC Converter With Considering Both Inductor Resistance and Conduction Voltages
}

\author{
Hung-Chi Chen, Member, IEEE, and Jhen-Yu Liao
}

\begin{abstract}
The full-bridge converter is often connected between the ac grid and the dc bus. In the conventional multiloop control, the inner current control loop shapes the ac-side current waveform, and the outer voltage control loop regulates the dc-bus voltage. In this paper, the single-loop bidirectional current sensorless control (BCSC) for the full-bridge ac/dc converter with considering both the inductor resistance and conduction voltage is first proposed. The average-value behavior of the full-bridge ac/dc converter is analyzed and it is simplified to an equivalent single-switch model. Based on this developed equivalent model, BCSC is designed and implemented in the FPGA-based system. There is only voltage control loop in the proposed BCSC (i.e., no current control loop), but $\mathrm{BCSC}$ is able to regulate the dc-bus voltage and shape the acside current. The provided results in both the rectifier operation and the inverter operation demonstrate the effectiveness of the proposed BCSC.
\end{abstract}

Index Terms-Current sensorless control, full-bride converter.

\section{INTRODUCTION}

$\mathbf{T}$ HE four-switch full-bridge converter is a basic circuit topology in the power electronics due to its bidirectional ability in both the $\mathrm{dc} / \mathrm{dc}$ conversion and the ac/dc conversion. In the past years, the pulse-width-modulation (PWM) rectifiers had been presented to replace the diode rectifiers for their high power-factor ability. Many topologies of PWM rectifiers had been studied. The full-bridge ac/dc converter as shown in Fig. 1 claims to provide the better input current waveform and the ability of the bidirectional operation [1]-[3].

Recently, the full-bridge ac/dc converters are widely used in the single-phase rectifier application and the single-phase inverter applications, such as the power factor correction (PFC) [4], [5], the front end of the motor drive [6], [7], the photovoltaic generation system [8]-[11], the uninterruptible power source [12], and the dc microgrid system [13], [14].

Manuscript received November 1, 2012; revised February 19, 2013 and May 20, 2013; accepted May 21, 2013. Date of current version October 15, 2013. This work was supported by the National Science Council of Taiwan under Contract NSC 102-ET-E-009-004-ET.This paper was presented in part at IEEE Energy Conversion Congress and Exposition, Raleigh, NC, USA, September 15-20, 2012. Recommended for publication by Associate Editor A. Prodic.

The authors are with the Department of Electrical and Computer Engineering, National Chiao Tung University, Hsinchu 30010, Taiwan (e-mail: hcchen@mail.nctu.edu.tw; popoid1003@hotmail.com).

Color versions of one or more of the figures in this paper are available online at http://ieeexplore.ieee.org.

Digital Object Identifier 10.1109/TPEL.2013.2265323

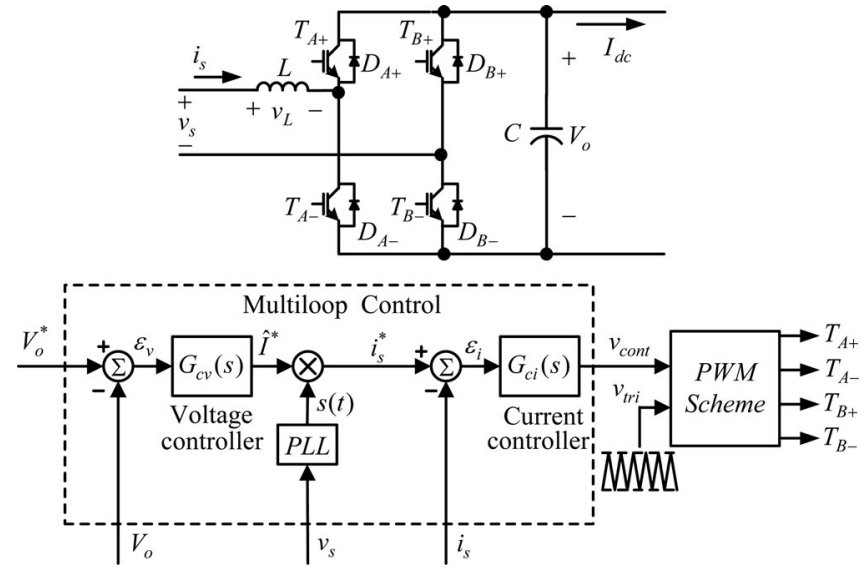

Fig. 1. Full-bridge ac/dc converter with the conventional multiloop control.

The multiloop control as shown in Fig. 1 is often used to control the full-bridge ac/dc converter [4]-[19]. There are two control loops cascaded in the multiloop control. The outer voltage control loop regulates the dc-bus voltage $V_{o}$ and the inner control loop shapes the ac-side current $i_{s}$. The ac-side voltage $\operatorname{sign}\left(I_{\mathrm{dc}}\right)$ is also sensed to obtain the phase information of the ac grid for the inner current control loop.

In [4], the dual hysteresis current control loop was proposed to improve the current shaping performance. Additional switches were connected to the four-switch full-bridge converter to reduce the dc-bus voltage ripple and thus, increase the power density [5]. The multiloop control was modified to reduce the circulating current in parallel full-bridge converters in [6], [7], and [10]. In addition, the maximum power point tracking scheme and the multiloop control were integrated to control the PVbased grid-tied system [8], [9]. For the parallel full-bridge inverters, the multiloop control with the centralized voltage loop and the individual current loops was proposed in [12].

For the thyristor-based bidirectional ac/dc converter in [15], the voltage sensorless concept was implemented with the multiloop control in which both the ac-side voltage and the dc-bus voltage were estimated from the sensed rising/falling rate of the inductor current. A PWM strategy for full-bridge ac/dc converter was proposed in [16] where two switches switch in the carrier frequency and the other two switches switch in the line frequency.

In current control loop, relatively high-resolution current $\mathrm{A} / \mathrm{D}$ conversion is required over a wide range of the sensed ac-side currents, which increases the complexity, the power 
TABLE I

SUMMARIZED RESUlTS FOR VARIOUS CURRENT SENSORLESS CONTROL METHODS

\begin{tabular}{|c|c|c|c|c|c|c|c|}
\hline & & {$[19]$} & {$[20]$} & [21] & {$[22]$} & [23] & Proposed \\
\hline \multicolumn{2}{|c|}{ Published Year } & 1995 & 2000 & 2004 & 2009 & 2010 & BCSC \\
\hline \multirow[t]{2}{*}{ Topology } & $\begin{array}{c}\text { Diode rectifier } \\
+ \text { Boost converter }\end{array}$ & $\mathrm{V}$ & $\mathrm{V}$ & $\mathrm{V}$ & $\mathrm{V}$ & $\mathrm{V}$ & \\
\hline & $\begin{array}{l}\text { Full-Bridge } \\
\text { converter }\end{array}$ & & & & & & $\mathrm{v}$ \\
\hline \multirow{2}{*}{$\begin{array}{l}\text { Sensorless } \\
\text { Control } \\
\end{array}$} & Multiloop control & & & $\mathrm{V}$ & & $\mathrm{V}$ & \\
\hline & Single-loop control & $\mathrm{V}^{*}$ & $\mathrm{v}$ & & $\mathrm{v}$ & & $\mathrm{v}$ \\
\hline \multirow{4}{*}{$\begin{array}{c}\text { Consideratio } \\
\mathrm{n} \text { of }\end{array}$} & the inductance & $\mathrm{v}$ & $\mathrm{v}$ & $\mathrm{v}$ & $\mathrm{V}$ & $\mathrm{v}$ & $\mathrm{V}$ \\
\hline & the resistance & & & $\mathrm{V}$ & $\mathrm{V}$ & & $\mathrm{V}$ \\
\hline & $\begin{array}{l}\text { the conduction } \\
\text { voltages }\end{array}$ & & & $\mathrm{v}$ & $\mathrm{V}$ & & $\mathrm{v}$ \\
\hline & the time delay & & & & & $\mathrm{V}$ & \\
\hline \multirow{6}{*}{ Parameters } & Inductance $(m H)$ & 10 & & 1.2 & 4.65 & & 4.6 \\
\hline & Capacitance & 2200 & & 2200 & 560 & & 1410 \\
\hline & $\begin{array}{c}\text { Switching frequency } \\
(\mathrm{kHz})\end{array}$ & 19.2 & 2.5 & 160 & 25 & 73 & 40 \\
\hline & AC-side voltage & 115 & & 55 & 110 & 220 & 110 \\
\hline & DC bus voltage $(V)$ & 215 & & 100 & 300 & & 200 \\
\hline & Power $(W)$ & 1000 & & 400 & 500 & & 500 \\
\hline
\end{tabular}

* means that additional load current is measured.

consumption, and the cost of the controller implementation [17]. In [17] and [18], the comparator-based sensing methods without using the real analog-to-digital converters (ADCs) were proposed to save the hardware cost in the multiloop control.

In order to remove the current measurement, numerous approaches were proposed in [19]-[23] and tabulated in Table I. Like the voltage sensorless concept in [15], the inductor current in continuous conducting mode (CCM) was rebuilt by the sensed voltages [23]. All the listed current sensorless control methods were developed for the single-phase diode rectifier plus the boost converter, but not for bidirectional circuits. In addition, because that the rules in CCM are significantly simpler than those in discontinuous conduction mode (DCM), all the listed methods are developed based on CCM. Therefore, to guarantee operating in CCM during the whole cycle, bulky inductors are often selected [19], [21], [22].

Both voltage control loop and current control loop exist in [21] and [23]. But only single voltage loop is included in [19], [20], and [22]. Recently, to obtain the accurate current estimation and reduce the accumulative error, the inductance, the inductor resistance, and the conduction voltage had been considered in [21] and [22]. The time delay had also been considered in [23]. It shows that considering only inductance cannot meet the current sensorless operation of the PFC function. In this paper, the bidirectional current sensorless control (BCSC) for the full-bridge converter is first proposed. Only the voltage control loop is included in the proposed BCSC, and both the inductor resistance and the conduction voltage are considered.

This paper is organized as following. In first, the behavior of a full-bridge converter is studied and it can be simplified to an equivalent single-switch model. Based on the developed model, the BCSC is proposed. By considering the power flow direction and the polarity of the ac-side voltage, the four switching

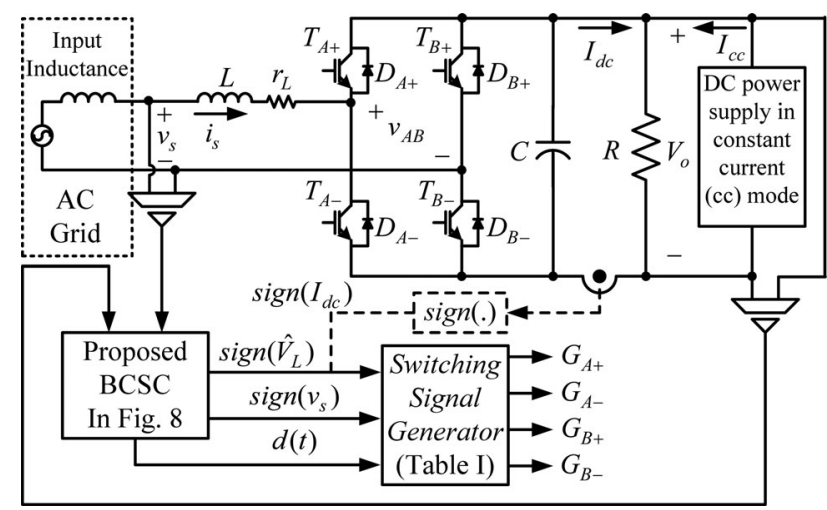

Fig. 2. Full-bridge ac/dc converter with the proposed control method.

signals are generated. Finally, the provided simulation and the experiment results are able to verify the proposed BCSC.

\section{Single-Switch Model For THE FULL-BRIDGE AC/DC CONVERTER}

Fig. 1 shows the full-bridge ac/dc converter with the proposed control configuration. A full-bridge converter with four switches is connected between the ac grid and the dc bus. Both the ac-side voltage $v_{s}$ and the dc-bus voltage $V_{o}$ are sensed. The four switching signals $\mathrm{G}_{\mathrm{A}+}, \mathrm{G}_{\mathrm{A}-}, \mathrm{G}_{B+}$, and $\mathrm{G}_{B-}$ are generated from the switching signal generator according to three input signals $\operatorname{sign}\left(\hat{V}_{L}\right)$, sign $\left(v_{s}\right)$, and $d(t)$. The switching signal $d(t)$ is generated from the proposed BCSC and the sign function $\operatorname{sign}(x)$ is denoted as

$$
\operatorname{sign}(x)=\left\{\begin{array}{ll}
1, & \text { when } x \geq 0 \\
0, & \text { when } x<0
\end{array} .\right.
$$

In order to represent the behavior of the full-bridge converter accurately, the inductor resistance and the voltage drops of the semiconductor devices are also considered in this paper. In addition, CCM is assumed during the line cycle.

A dc power supply operated in constant current (cc) mode is connected to the dc bus to represent the direct power flow to the dc bus. Since the yielded current $I_{\mathrm{cc}}$ of the connected dc power supply cannot be negative (i.e., $I_{\mathrm{cc}} \geq 0$ ), a resistor $R$ is also connected in the dc bus to represent the load power in dc side.

When the power flow $V_{o} I_{\mathrm{cc}}$ is larger than the load power $V_{\mathrm{o}}^{2} / R$ (i.e., the negative current $I_{\mathrm{dc}}<0$ ), the dc-bus voltage $V_{o}$ would rise due to the capacitor $C$ connected in the dc bus. In order to regulate the dc-bus voltage $V_{o}$, excess power should be transferred from dc-side bus to ac grid and thus, the full-bridge converter needs to operate at the inverter mode. Contrarily, the full-bridge converter needs to operate at the rectifier mode when the power flow $V_{o} I_{\mathrm{cc}}$ is smaller than the load power $V_{\mathrm{o}}^{2} / R$ (i.e., the positive current $I_{\mathrm{dc}}>0$ ).

Therefore, the signal $\operatorname{sign}\left(I_{\mathrm{dc}}\right)$ shown as the dashed line in Fig. 2 is helpful in the derivation of the following singleswitch model of the full-bridge converter. However, this signal $\operatorname{sign}\left(I_{\mathrm{dc}}\right)$ can be equivalently replaced by the other sign value signal in the proposed BCSC. Therefore, the proposed control method does not need to sense any current in fact. 
TABLE II

Summary OF SWITCHING Signal COMBINATION

\begin{tabular}{|c|c|c|c|c|c|c|c|}
\hline $\operatorname{sign}\left(I_{d c}\right)$ & $\operatorname{sign}\left(v_{s}\right)$ & $d(t)$ & $G_{A+}$ & $G_{A-}$ & $G_{B+}$ & $G_{B-}$ & $\begin{array}{c}\text { Flowing } \\
\text { path }\end{array}$ \\
\hline \multirow{4}{*}{$\begin{array}{c}1 \\
\text { (Rectifier) }\end{array}$} & \multirow{2}{*}{$\begin{array}{c}1 \\
\text { (Positive } \\
\text { voltage) }\end{array}$} & 1 & OFF & ON & OFF & OFF & $\begin{array}{l}T_{A-}, \\
D_{B-}\end{array}$ \\
\hline & & 0 & OFF & OFF & OFF & OFF & $\begin{array}{l}D_{A+}, \\
D_{B-}\end{array}$ \\
\hline & \multirow{2}{*}{$\begin{array}{c}0 \\
\text { (Negative } \\
\text { voltage) }\end{array}$} & 1 & $\mathrm{ON}$ & OFF & OFF & OFF & $\begin{array}{l}T_{A+}, \\
D_{B+}\end{array}$ \\
\hline & & 0 & OFF & OFF & OFF & OFF & $\begin{array}{l}D_{A_{-}}, \\
D_{B+}\end{array}$ \\
\hline \multirow{4}{*}{$\begin{array}{c}0 \\
\text { (Inverter) }\end{array}$} & \multirow{2}{*}{$\begin{array}{c}1 \\
\text { (Positive } \\
\text { voltage) }\end{array}$} & 1 & ON & OFF & OFF & OFF & $\begin{array}{l}T_{A+}, \\
D_{B+} \\
\end{array}$ \\
\hline & & 0 & ON & OFF & OFF & $\mathrm{ON}$ & $\begin{array}{l}T_{A+}, \\
T_{B-} \\
\end{array}$ \\
\hline & \multirow{2}{*}{$\begin{array}{c}0 \\
\text { (Negative } \\
\text { voltage) }\end{array}$} & 1 & OFF & ON & OFF & OFF & $\begin{array}{l}T_{A-}, \\
D_{B-}\end{array}$ \\
\hline & & 0 & OFF & ON & $\mathrm{ON}$ & OFF & $\begin{array}{l}T_{A-}, \\
T_{B+}\end{array}$ \\
\hline
\end{tabular}

According to the switching signal $d(t)$, the sign value sign $\left(v_{s}\right)$ of input voltage $v_{s}$ and the power direction signal sign $\left(I_{\mathrm{dc}}\right)$, four switching signals $G_{A+}, G_{A-}, G_{B+}$, and $G_{B-}$ are generated based on the following rules. The summaries of generating rules are tabulated in Table II

$$
\begin{aligned}
& G_{A+}=\overline{\operatorname{sign}\left(I_{\mathrm{dc}}\right)} \cdot \operatorname{sign}\left(v_{s}\right)+\operatorname{sign}\left(I_{\mathrm{dc}}\right) \cdot \overline{\operatorname{sign}\left(v_{s}\right)} \cdot d(t)(2) \\
& G_{A-}=\overline{\operatorname{sign}\left(I_{\mathrm{dc}}\right)} \cdot \overline{\operatorname{sign}\left(v_{s}\right)}+\operatorname{sign}\left(I_{\mathrm{dc}}\right) \cdot \operatorname{sign}\left(v_{s}\right) \cdot d(t)(3) \\
& G_{B+}=\overline{\operatorname{sign}\left(I_{\mathrm{dc}}\right)} \cdot \overline{\operatorname{sign}\left(v_{s}\right)} \cdot \overline{d(t)} \\
& G_{B-}=\overline{\operatorname{sign}\left(I_{\mathrm{dc}}\right)} \cdot \operatorname{sign}\left(v_{s}\right) \cdot \overline{d(t)} \text {. }
\end{aligned}
$$

In the following sections, the behaviors at the rectifier mode and the inverter mode are studied, respectively.

\section{A. Rectifier Operation $\left(\operatorname{sign}\left(I_{\mathrm{dc}}\right)=1\right)$}

At the rectifier operation $\operatorname{sign}\left(I_{\mathrm{dc}}\right)=1$, only one switch switches with the switching signal $d(t)$ and the other three switches block. When the ac-side voltage is positive $v_{s}>0$, only the switch $T_{A-}$ switches with the switching signal $d(t)$ and the other switches keep turning OFF. As the ac-side voltage is negative $v_{s}<0$, only the switch $T_{A+}$ switches with the signal $d(t)$.

According to (2)-(5), the gate signals during the positive input voltage $\left(\operatorname{sign}\left(v_{s}\right)=1\right)$ and during the negative input voltage $\left(\operatorname{sign}\left(v_{s}\right)=0\right)$ can be summarized as (6) and (7), respectively. Switching signal $d(t)$ is either $d(t)=1$ or $d(t)=0$

$$
\begin{aligned}
G_{A+}= & 0, G_{A-}=d(t), G_{B+}=0, G_{B-}=0, \\
& \text { when positive voltage } \operatorname{sign}\left(v_{s}\right)=1 \\
G_{A+}= & d(t), G_{A-}=0, G_{B+}=0, G_{B-}=0,
\end{aligned}
$$

$$
\text { when negative voltage } \operatorname{sign}\left(v_{s}\right)=0 \text {. }
$$

The resulting current flowing paths during positive input voltage and negative input voltage are plotted in Figs. 3 and 4,

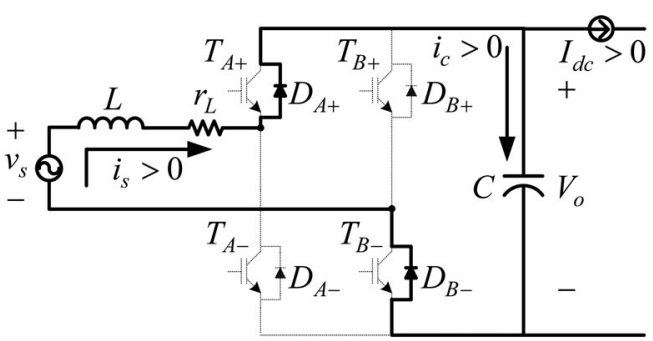

(a)

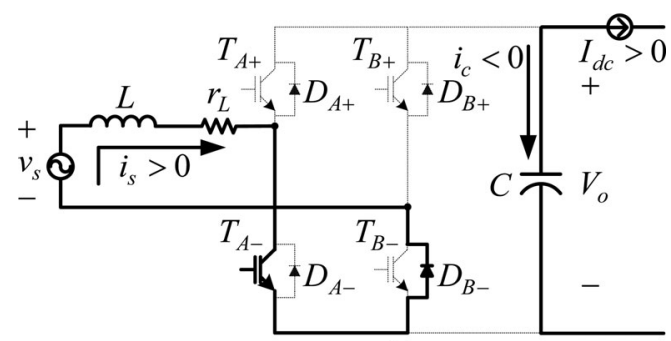

(b)

Fig. 3. Current flowing path during positive input voltage $v_{s}>0$ (a) when the switching signal $d(t)=1$, (b) when $d(t)=0$.

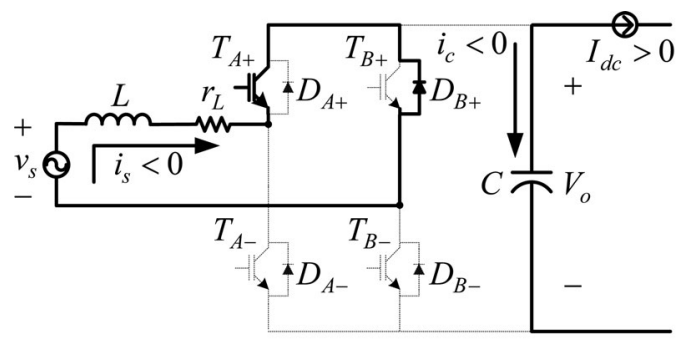

(a)

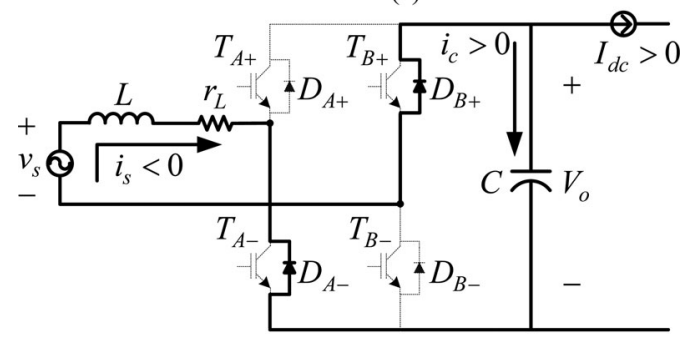

(b)

Fig. 4. Current flowing path during negative input voltage $v_{s}<0$ (a) when the switching signal $d(t)=1$, (b) when $d(t)=0$.

respectively. When the switching signal $d(t)=1$, the inductor voltage of Figs. 3(a) and 4(a) can be expressed as (8) and (9), respectively

$v_{L}=v_{s}-V_{F}-r_{L} i_{s}, \quad$ when positive voltage $\operatorname{sign}\left(v_{s}\right)=1$

$v_{L}=v_{s}+V_{F}-r_{L} i_{s}, \quad$ when negative voltage $\operatorname{sign}\left(v_{s}\right)=0$

where the constant $V_{F}$ is assumed to represent the total conduction drops through the flowing path. Then, the inductor voltage in (8) and (9) for $d(t)=1$ can be combined to the following 


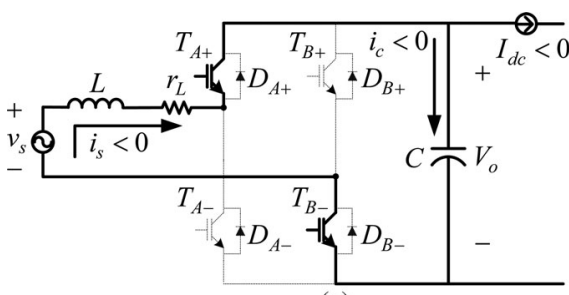

(a)

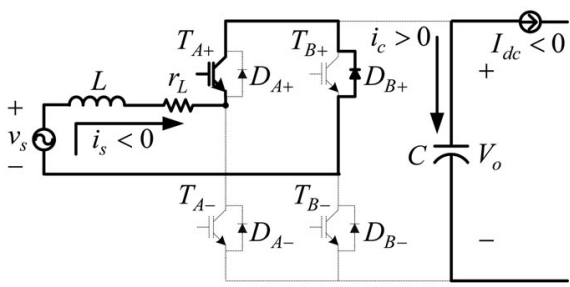

(b)

Fig. 5. Current flowing path during positive input voltage $v_{s}>0$ (a) when the switching signal $d(t)=1,(\mathrm{~b})$ when $d(t)=0$.

equation:

$$
v_{L}=v_{s}-\left[2 \operatorname{sign}\left(v_{s}\right)-1\right] V_{F}-r_{L} i_{s}, \quad \text { when } d(t)=1 .
$$

Similarly, the inductor voltage of Figs. 3(b) and 4(b) for $d(t)$ $=0$ can be expressed as (11) and (12), respectively

$$
\begin{aligned}
v_{L}= & v_{s}-V_{F}-r_{L} i_{s}-V_{o}, \\
& \quad \text { when positive voltage } \operatorname{sign}\left(v_{s}\right)=1 \\
v_{L}= & v_{s}+V_{F}-r_{L} i_{s}+V_{o},
\end{aligned}
$$$$
\text { when negative voltage } \operatorname{sign}\left(v_{s}\right)=0 \text {. }
$$

These two equations can be combined to the following equation

$$
v_{L}=v_{s}-\left[2 \operatorname{sign}\left(v_{s}\right)-1\right] V_{F}-r_{L} i_{s}-\left[2 \operatorname{sign}\left(v_{s}\right)-1\right] V_{o},
$$

$$
\text { when } d(t)=0 \text {. }
$$

\section{B. Inverter Operation $\left(\operatorname{sign}\left(I_{\mathrm{dc}}\right)=0\right)$}

At the inverter operation $\operatorname{sign}\left(I_{\mathrm{dc}}\right)=0$, two switches switch with the switching signal $d(t)$ and the others switch with the line voltage sign. When the ac-side voltage is positive $v_{s}>0$, the switch $T_{A+}$ keeps turning $\mathrm{ON}$ and the switch $T_{B-}$ switches with the complement switching signal $\overline{d(t)}$. The other two switches $T_{B+}$ and $T_{A-}$ keep turning OFF. As the ac-side voltage turns to negative $v_{s}<0$, the switch $T_{A-}$ keeps turning $\mathrm{ON}$ and the switch $T_{B+}$ switches with the complement switching signal $\overline{d(t)}$.

The gate signals during the positive input voltage $\left(\operatorname{sign}\left(v_{s}\right)=\right.$ $1)$ and during the negative input voltage $\left(\operatorname{sign}\left(v_{s}\right)=0\right)$ can be summarized as (14) and (15), respectively

$$
\begin{aligned}
& G_{A+}=1, G_{A-}=0, G_{B+}=0, G_{B-}=\overline{d(t)} \\
& G_{A+}=0, G_{A-}=1, G_{B+}=\overline{d(t)}, G_{B-}=0 .
\end{aligned}
$$

In addition, the resulting current flowing paths during positive input voltage and negative input voltage are plotted in Figs. 5 and 6 , respectively. When $d(t)=1$, the inductor voltage

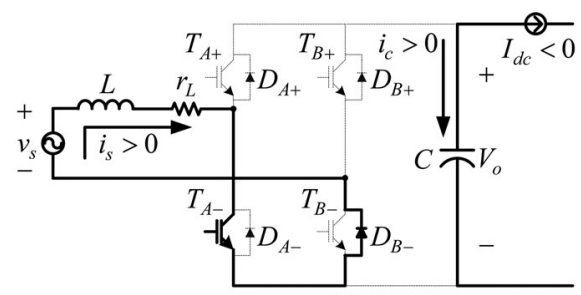

(a)

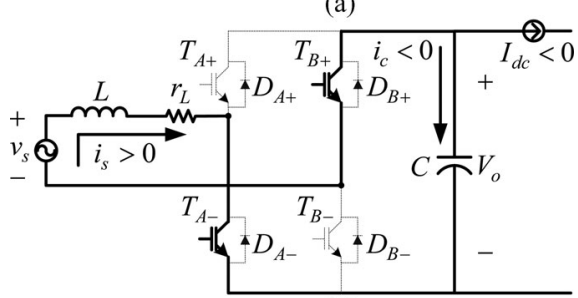

(b)

Fig. 6 Current flowing path during negative input voltage $v_{s}<0$ (a) when the switching signal $d(t)=1$, (b) when $d(t)=0$.

of Figs. 5(a) and 6(a) can be expressed as (16) and (17), respectively

$$
\begin{aligned}
v_{L}= & v_{s}+V_{F}-r_{L} i_{s}, \\
& \text { when positive voltage } \operatorname{sign}\left(v_{s}\right)=1 \\
v_{L}= & v_{s}-V_{F}-r_{L} i_{s},
\end{aligned}
$$

when negative voltage $\operatorname{sign}\left(v_{s}\right)=0$.

From (16) and (17), the inductor voltage for $d(t)=1$ can be simplified to the following equation:

$$
v_{L}=v_{s}+\left[2 \operatorname{sign}\left(v_{s}\right)-1\right] V_{F}-r_{L} i_{s}, \quad \text { when } d(t)=1 .
$$

Likewise, from Figs. 5(b) and 6(b), the inductor voltage for $d(t)=0$ can be represented together

$$
\begin{aligned}
v_{L}= & v_{s}+\left[2 \operatorname{sign}\left(v_{s}\right)-1\right] V_{F}-r_{L} i_{s}-\left[2 \operatorname{sign}\left(v_{s}\right)-1\right] V_{o}, \\
& \text { when } d(t)=0 .
\end{aligned}
$$

\section{Equivalent Single-Switch Model}

By considering both (10) at the rectifier mode $\operatorname{sign}\left(I_{\mathrm{dc}}\right)=$ 1 and (18) at the inverter mode $\operatorname{sign}\left(I_{\mathrm{dc}}\right)=0$, the inductor voltage can be expressed in terms of the power direction signal $\operatorname{sign}\left(I_{\mathrm{dc}}\right)$ and the voltage polarity signal $\operatorname{sign}\left(v_{s}\right)$.

$$
v_{L}=v_{s}-K_{F} V_{F}-r_{L} i_{s}, \quad \text { when } d(t)=1 .
$$

Similarly, from (13) and (19), the inductor voltage for $d(t)=$ 0 can be expressed as

$$
v_{L}=v_{s}-K_{F} V_{F}-r_{L} i_{s}-K_{o} V_{o}, \quad \text { when } d(t)=0 .
$$

Therefore, according to (20) and (21), the equivalent singleswitch model for the bidirectional full-bridge ac/dc converter can be plotted in Fig. 7 where $K_{F}=\left[2 \operatorname{sign}\left(I_{\mathrm{dc}}\right)-\right.$ 1] $\left[2 \operatorname{sign}\left(v_{s}\right)-1\right]$ and $K_{o}=\left[2 \operatorname{sign}\left(v_{s}\right)-1\right]$ are two gains to represent the effects of the total conduction voltage drop $V_{F}$ and the dc-side voltage $V_{o}$, respectively. 


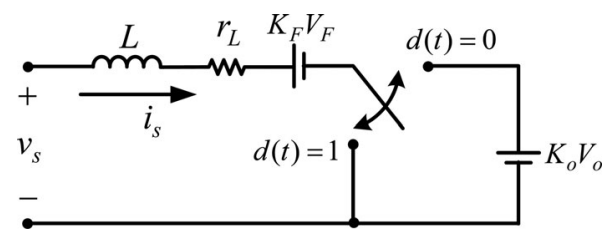

Fig. 7. Equivalent single-switch modeling of the full-bridge AC/DC converter.

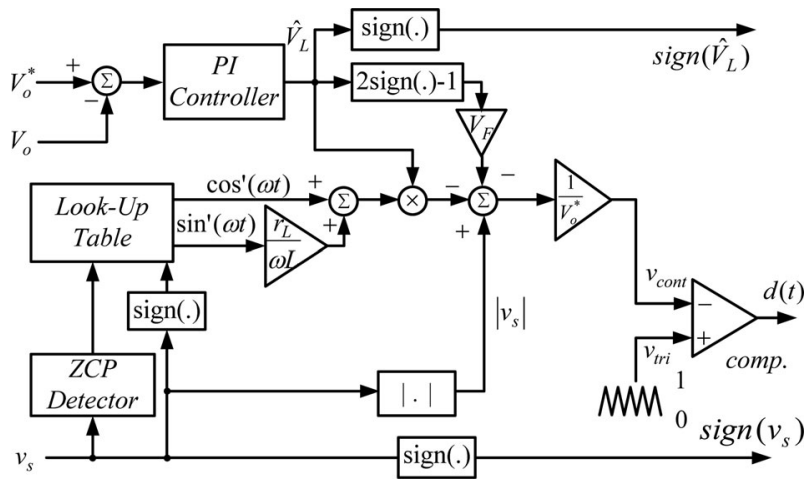

Fig. 8. Proposed BCSC.

\section{PROpOSED CONTROLlER}

From the developed equivalent single-switch model of the full-bridge ac/dc converter, the average inductor voltage $\left\langle v_{L}\right\rangle_{T_{s}}$ can be calculated with multiplying (20) by the conducting time $T_{s} \cdot\langle d(t)\rangle_{T_{s}}$ and multiplying (21) by the blocking time $T_{s}$. $\left(1-\langle d(t)\rangle_{T_{s}}\right)$ where $\left\langle v_{\mathrm{L}}\right\rangle_{T_{s}}$ represents the average value of the inductor voltage $v_{\mathrm{L}}$ within the switching period $T_{s}$.

Then, the average inductor voltage $\left\langle v_{L}\right\rangle_{T_{s}}$ can be expressed as

$$
\left\langle v_{L}\right\rangle_{\mathrm{T}_{s}}=v_{s}-K_{F} V_{F}-r_{L} i_{s}-K_{o}\left(1-\langle d(t)\rangle_{T_{s}}\right) V_{o} .
$$

\section{A. $B C S C$}

The proposed BCSC is plotted in Fig. 8 where the triangular signal $v_{\text {tri }}$ varies between 0 and 1 periodically. A proportionalintegral (PI)-type voltage controller is used to regulate the dc-bus voltage $V_{o}$ and shape the ac-side current waveform effectively. Two signals $\cos ^{\prime}(\omega t)$ and $\sin ^{\prime}(\omega t)$ are generated from the action of the look-up table. Both $\cos ^{\prime}(\omega t)$ and $\sin ^{\prime}(\omega t)$ are synchronized to the zero-crossing instants of the ac-side voltage $v_{s}$ via the zero-crossing point detector (ZCP Detector).

The switching signal $d(t)$ is obtained from the comparison of the control signal $v_{\text {cont }}$ and the triangular signal $v_{\text {tri }}$. Thus, the duty ratio of the switching signal $d(t)$ can be expressed as

$$
\langle d(t)\rangle_{T_{s}}=1-\left\langle v_{\mathrm{cont}}\right\rangle_{T_{s}} .
$$

In order to yield a sinusoidal ac-grid current $i_{s}=\hat{I}_{s} \sin (\omega t)$ in phase with the ac-grid voltage $v_{s}$, the average inductor voltage $\left\langle v_{L}\right\rangle_{T_{s}}$ must follow the function $\cos (\omega t)$. Thus, the desired average inductor voltage can be expressed as $\left\langle v_{L}\right\rangle_{T_{s}}=\hat{\mathrm{V}}_{L} \cos (\omega t)$ where the bipolar signal $\hat{V}_{L}$ represents the inductor voltage amplitude. Since the average inductor voltage $\left\langle v_{L}\right\rangle_{T_{s}}$ is expressed as $\hat{\mathrm{V}}_{L} \cos (\omega t)$, the yielded average inductor current $\left\langle i_{L}\right\rangle_{T_{s}}$ would be

$$
\left\langle i_{L}\right\rangle_{T_{s}}=\frac{\hat{\mathrm{V}}_{L}}{\omega L} \sin (\omega t)=\hat{\mathrm{I}}_{s} \sin (\omega t) .
$$

By substituting $\left\langle v_{L}\right\rangle_{T_{\mathrm{s}}}=\hat{\mathrm{V}}_{L} \cos (\omega t)$, (23) and (24) into (22), the average control signal $\left\langle v_{\text {cont }}\right\rangle_{T_{s}}$ needs to be

$$
\left\langle v_{\mathrm{cont}}\right\rangle_{T_{s}}=\frac{1}{V_{o}}\left\{\begin{array}{l}
\frac{v_{s}}{\left[2 \operatorname{sign}\left(v_{s}\right)-1\right]}-\left[2 \operatorname{sign}\left(I_{\mathrm{dc}}\right)-1\right] V_{F} \\
-\frac{\hat{\mathrm{V}}_{L}}{\left[2 \operatorname{sign}\left(v_{s}\right)-1\right]}\left[\cos (\omega t)+\frac{r_{L}}{\omega L} \sin (\omega t)\right]
\end{array}\right\} .
$$

The average value of the yielded instantaneous power $p_{s}=$ $\left\langle v_{s} \cdot i_{s}\right\rangle_{T_{s}}$ within the switching period $T_{s}$ becomes

$$
p_{s}=\frac{\hat{V}_{s} \hat{I}_{s}}{2}(1-\cos 2 \omega t)=\frac{\hat{V}_{s}}{2 \omega L} \hat{\mathrm{V}}_{L}-\frac{\hat{V}_{s}}{2 \omega L} \hat{\mathrm{V}}_{L} \cos 2 \omega t .
$$

Furthermore, the average power $P$ from ac grid to dc bus is the average value of the instantaneous power $\left\langle v_{s} \cdot i_{s}\right\rangle_{T}$ within the line period $\mathrm{T}=\omega / 2 \pi$.

$$
P=\left\langle v_{s} \cdot i_{s}\right\rangle_{T}=\frac{\hat{V}_{s}}{2 \omega L} \hat{V}_{L} .
$$

\section{B. Replacement for sign $I_{\mathrm{dc}}$}

Equation (27) is very important for the proposed BCSC. First, the signal $\hat{V}_{L}$ is bipolar, and thus, the yielded power flow $P$ is bidirectional. It means that the proposed BCSC is able to operate in both the rectifier operation and the inverter operation.

In addition, the sign value $\operatorname{sign}\left(\hat{\mathrm{V}}_{L}\right)=1$ means that the average power is positive $P>0$ (i.e., rectifier operation with $\left.\operatorname{sign}\left(I_{\mathrm{dc}}\right)=1\right)$. Zero value $\operatorname{sign}\left(\hat{\mathrm{V}}_{L}\right)=0$ means negative average power $P<0$ (i.e., inverter operation with $\operatorname{sign}\left(I_{\mathrm{dc}}\right)=0$ ). Therefore, the sign value $\operatorname{sign}\left(\hat{\mathrm{V}}_{L}\right)$ can be used to equivalently replace for the sign value $\operatorname{sign}\left(I_{\mathrm{dc}}\right)$ shown in Table I, Fig. 2, and (25). The resulting control signal $v_{\text {cont }}$ can be obtained by

$$
\begin{aligned}
\left\langle v_{\text {cont }}\right\rangle_{T_{s}}= & \frac{1}{V_{o}^{*}}\left\{\left|v_{s}\right|-\left[2 \operatorname{sign}\left(\hat{V}_{L}\right)-1\right] V_{F}-\hat{\mathrm{V}}_{L}\right. \\
& {\left.\left[\cos ^{\prime}(\omega t)+\frac{r_{L}}{\omega L} \sin ^{\prime}(\omega t)\right]\right\} }
\end{aligned}
$$

where $\cos ^{\prime}(\omega t)=K_{o} \cos (\omega t)$ and $\sin ^{\prime}(\omega t)=K_{o} \sin (\omega t)$. The first term in the right-hand of (25) is equal to the rectified input voltage $\left|v_{s}\right|$.

Based on (28), the control signal $v_{\text {cont }}$ of the proposed BCSC is plotted in Fig. 8. Because that the signal $\operatorname{sign}\left(I_{\mathrm{dc}}\right)$ is equivalently replaced by the sign value $\operatorname{sign}\left(\hat{\mathrm{V}}_{L}\right)$, the proposed BCSC does not need to sense the dc bus current $I_{\mathrm{dc}}$ in fact.

\section{PI-Type Controller}

The transfer function of the output voltage perturbation $\Delta V_{o}$ due to the controller output signal $\Delta \hat{V}_{L}$ can be obtained from the instantaneous power balance $p_{s}=p_{C}+p_{\mathrm{dc}}$ between the acside power $p_{s}$, the dc-side delivered power $p_{\mathrm{dc}}$ and the capacitor power $p_{C}[10]$. 
From (22), the instantaneous power $p_{s}$ can be written as

$$
p_{s}=\frac{\hat{v}_{s}}{2 \omega L}\left(\hat{V}_{L}+\Delta \hat{V}_{L}\right)(1-\cos 2 \omega t)
$$

The dc-side delivered power $p_{\mathrm{dc}}$ with the small perturbation $\Delta p_{\mathrm{dc}}$ can be represented by the voltage command $\Delta V_{o}^{*}$ plus the perturbation $\Delta V_{o}$

$$
p_{\mathrm{dc}}=\frac{\left(V_{o}^{*}+\Delta V_{o}\right)^{2}}{R} \approx \frac{\left(V_{o}^{*}\right)^{2}}{R}+\frac{2 V_{o}^{*} \Delta V_{o}}{R} .
$$

The capacitor power $p_{C}$ can be represented by the voltage perturbation $\Delta V_{o}$

$$
p_{C}=\frac{d\left(\frac{1}{2} C\left(V_{o}^{*}+\Delta V_{o}\right)^{2}\right)}{d t} \approx C V_{o}^{*} \frac{d \Delta V_{o}}{d t} .
$$

By neglecting the double line-frequency component in the instantaneous power $p_{s}$, substituting (29)-(31) into the balance $p_{s}=p_{C}+p_{\mathrm{dc}}$ can yield the following small-signal transfer function $G_{s}(s)$

$$
G_{s}(s)=\frac{\Delta V_{\mathrm{o}}(s)}{\Delta \hat{\mathrm{V}}_{L}(s)}=\frac{\hat{V}_{s}}{2 \omega L C V_{o}^{*}} \frac{1}{\left(s+\frac{2}{R C}\right)} .
$$

Obviously, the small-signal behavior of the dc-bus voltage can be seen as a first-order model. Thus, the output voltage can be well regulated by including the PI-type controller in the proposed BCSC. After choosing the ratio of proportional gain $k_{P}$ and the integral gain $k_{I}$ to the pole of $G_{s}(s)$

$$
\frac{k_{I}}{k_{P}}=\frac{2}{R C}
$$

the closed-loop transfer function of the output voltage $\Delta V_{o}$ and the output voltage command $\Delta V_{o}^{*}$ can be obtained

$$
\frac{\Delta V_{o}(s)}{\Delta V_{o}^{*}(s)}=\frac{k_{P} \frac{\hat{V}_{s}}{2 \omega L C V_{o}^{*}}}{s+k_{P} \frac{\hat{V}_{s}}{2 \omega L C V_{o}^{*}}} .
$$

The closed-loop transfer function (34) can be seen as a low-pass filter. In order to avoid the effect of the double linefrequency voltage ripple in dc voltage bus, the cutoff frequency of (34) is chosen to be far smaller than the double line frequency. Therefore, the proportional gain can be chosen by

$$
k_{P}=\frac{\omega^{2} L C V_{o}^{*}}{50 \hat{V}_{s}} \text {. }
$$

\section{Simulation Results}

In this section, a series of computer simulations are performed to demonstrate the proposed BCSC. Some nominal values and circuit elements are listed in Table III. The simple PI-type voltage controller is used to regulate the output voltage and shape the current waveform.

In the simulation, a resistor $R=80 \Omega$ is connected to the dc bus and a current source $I_{\mathrm{cc}}$ is also connected to dc bus to represent the direct power flow to the dc bus. When the current source $I_{\mathrm{cc}}$ is zero, the full-bridge ac/dc converter needs to operate in the rectifier mode to transfer the average power $500 \mathrm{~W}$ from ac grid to dc bus to regulate the dc-bus voltage. Once the current $I_{\mathrm{cc}}$ is larger than $2.5 \mathrm{~A}$, the full-bridge converter
TABLE III

SIMULATION PARAMETERS

\begin{tabular}{|c|c|}
\hline DC-bus Voltage & $V_{o}^{*}=200 \mathrm{~V}$ \\
\hline Input Voltage & $110 \mathrm{Vrms}$ \\
\hline Input Frequency & $f=60 \mathrm{~Hz}$ \\
\hline Inductance & $L=4.6 \mathrm{mH}$ \\
\hline Equivalent resistance & $r_{L}=0.5 \Omega$ \\
\hline Capacitance & $C=1410 \mu \mathrm{F}$ \\
\hline Conduction voltage & $V_{F}=1.61 \mathrm{~V}$. \\
\hline Switching frequency & $f_{\text {tri }}=40 \mathrm{kHz}$ \\
\hline
\end{tabular}

needs to operate in the inverter mode to move some power from dc bus to ac grid.

\section{A. Pure Sinusoidal Grid Voltage}

The simulated waveforms when the full-bridge converter operates in the rectifier mode and in the inverter mode are plotted in Fig. 9(a) and (b), respectively. The input current $i_{s}$ is sinusoidal in phase with the input voltage $v_{s}$ and the voltage amplitude $\hat{V}_{L}$ is tuned to about $12.0 \mathrm{~V}$.

In Fig. 9(a), the current $I_{\mathrm{cc}}$ is set to zero, and the dc-side power is near $500 \mathrm{~W}$. To supply the dissipated energy of the resistor $R=80 \Omega$, the full-bridge converter needs to provide the power flow near $500 \mathrm{~W}$ to dc bus. Two synchronized signals $\cos ^{\prime}(\omega t)$ and $\sin ^{\prime}(\omega t)$ with double line frequency are generated from the alignments to the ZCPs of the ac-grid voltage. The voltage waveform $v_{\mathrm{ab}}$ shows that the used PWM method can be seen as the unipolar PWM method, but its ripple frequency is the same as the carrier frequency.

In this simulation, the inductor resistance and the conduction voltages of the semiconductor devices are not set to zero. With consideration of the loss of the full-bridge converter, the yielded average power is near $530 \mathrm{~W}$ larger than $500 \mathrm{~W}$.

On the contrary, when the current source $I_{\mathrm{cc}}$ is set to $5 \mathrm{~A}$, the total dc-side power now is $-500 \mathrm{~W}$. In order to regulate the dc-bus voltage, near $500 \mathrm{~W}$ power needs to be transferred from dc bus and thus, the full-bridge ac/dc converter turns to the inverter mode as shown in Fig 9(b). The yielded current is sinusoidal and the steady-state value of the voltage amplitude signal $\hat{V}_{L}$ is about $-9.7 \mathrm{~V}$. It is noted that the net power flow into ac grid is near $470 \mathrm{~W}$ smaller than $500 \mathrm{~W}$ due to the loss of the full-bridge converter.

Therefore, the steady-state amplitude $\hat{V}_{L}$ is not equalized. When the system absorbing power from ac grid, the steady state $\hat{V}_{L}$ is about $12.0 \mathrm{~V}$, but when the system is delivering power to the ac grid, the steady state $\hat{V}_{L}$ is about $-9.7 \mathrm{~V}$, not $-12 \mathrm{~V}$.

\section{B. Distorted Grid Voltage}

In the practical condition, the input voltage is often distorted due to the input inductance as shown in Fig. 2. To evaluate the performance of the proposed BCSC, the simulated waveforms with distorted input voltage at the rectifier mode and the inverter mode are plotted in Fig. 10(a) and (b), respectively. Although the ac-grid voltage $v_{s}$ is distorted, the yielded input currents $i_{s}$ are 


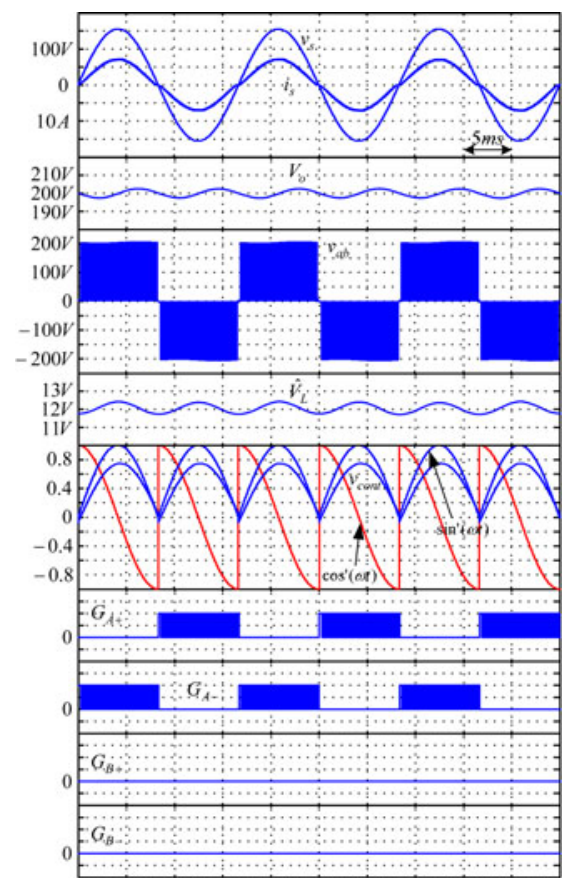

(a)

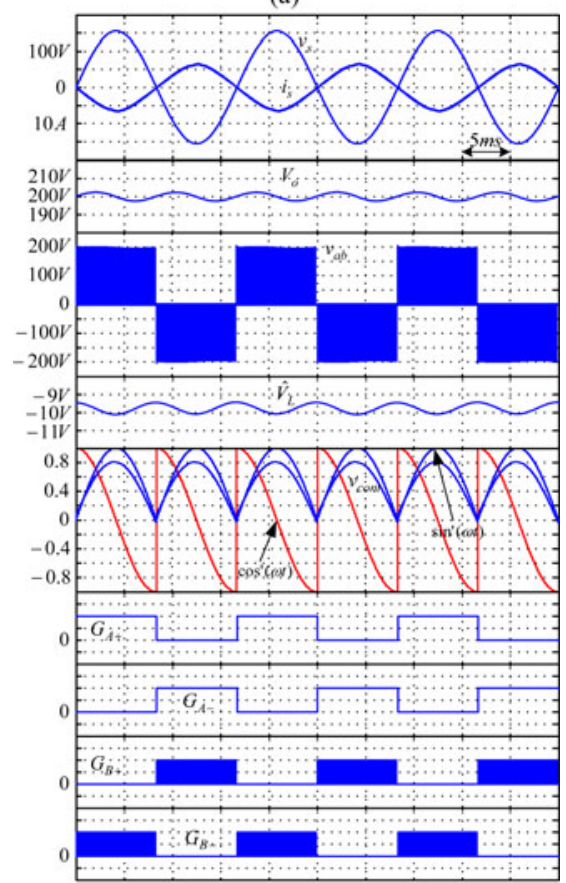

(b)

Fig. 9. Simulation results when the full-bridge converter operates (a) in rectifier mode with average input power $\approx 530 \mathrm{~W}\left(I_{\mathrm{cc}}=0 \mathrm{~A}\right),(\mathrm{b})$ in inverter mode with average input power $\approx-470 \mathrm{~W}\left(I_{\mathrm{cc}}=5 \mathrm{~A}\right)$.

closed to the sinusoidal waveforms. It shows that the proposed BCSC is also able to work well with the distorted input voltage.

The simulated steady-state waveforms without considering the inductor resistance and the conduction voltage (i.e., with considering only inductance) at the rectifier mode and the inverter mode are plotted in Fig. 11(a) and (b), respectively. The current initiates flowing at one $\mathrm{ZCP}$, but falls to zero prior to the next ZCP. The resulting zero-current duration makes power fac-

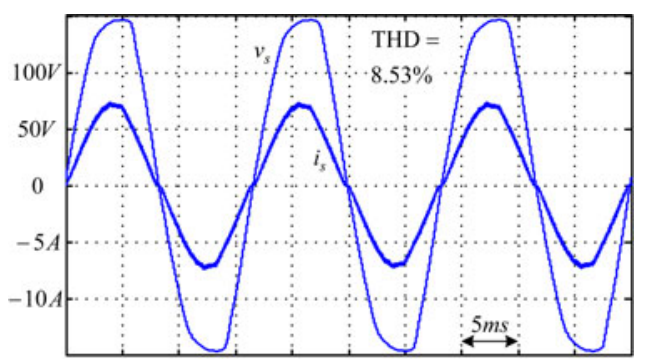

(a)

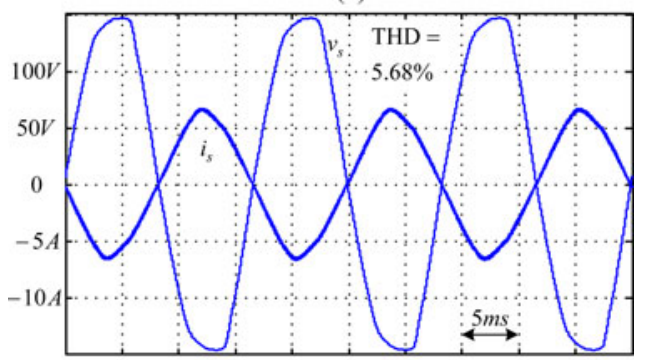

(b)

Fig. 10. Simulation results with distorted input voltage (a) in the rectifier mode with the average power $\approx 530 \mathrm{~W}$ (i.e., $I_{\mathrm{cc}}=0 \mathrm{~A}$ ), (b) in the inverter mode with the average power $\approx-470 \mathrm{~W}$ (i.e., $I_{\mathrm{cc}}=5 \mathrm{~A}$ ).

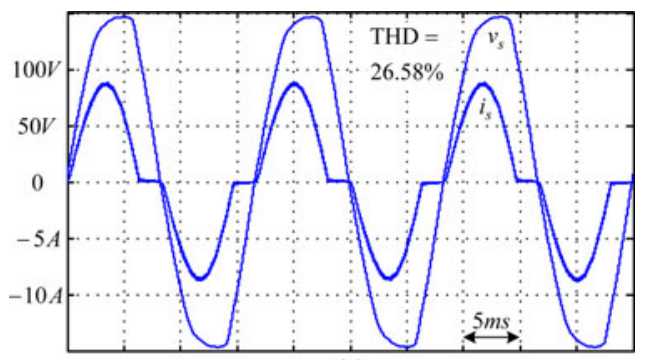

(a)

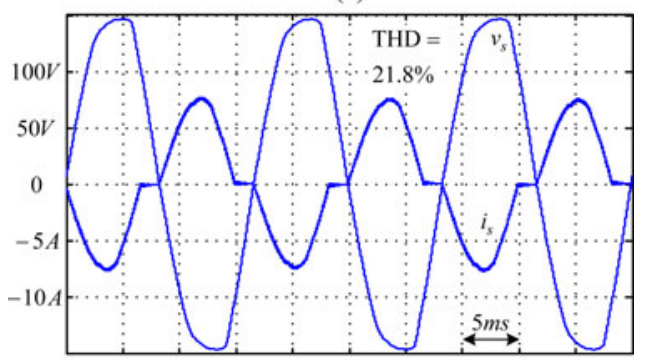

(b)

Fig. 11. Simulation results with considering only inductance (a) in the rectifier mode with the average power $\approx 530 \mathrm{~W}$ (i.e., $I_{\mathrm{cc}}=0 \mathrm{~A}$ ), (b) in the inverter mode with the average power $\approx-470 \mathrm{~W}$ (i.e., $I_{\mathrm{cc}}=5 \mathrm{~A}$ ).

tor leading and introduces larger current harmonics. The results show that the proposed BCSC without considering the parasitic effects is still stable, but yielded current waveform may not be acceptable.

In practice, the circuit parameters may change due to the heat from the power loss. As the inductor temperature increases, the resistance may increase but the inductance may decrease, which contributes to the circuit uncertainty.

With $10 \%$ changes of the circuit parameters $r_{L}=0.5 \Omega \times$ $1.1, L=4.6 \mathrm{mH} \times 0.9$ and no change of the control parameters $r_{L}=0.5 \Omega, L=4.6 \mathrm{mH}$, the simulated steady-state 


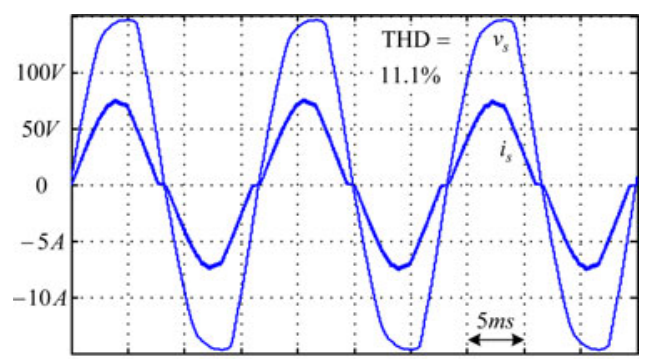

(a)

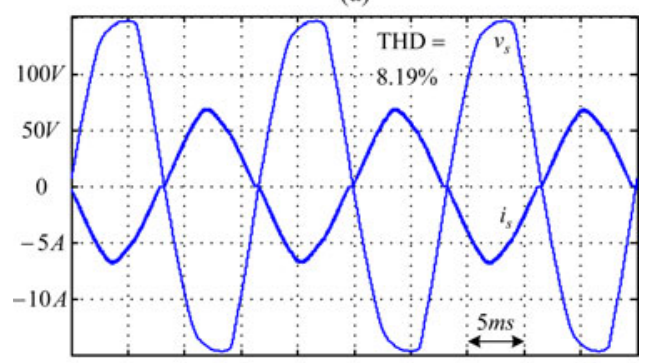

(b)

Fig. 12. Simulation results with circuit parameters $r_{L}=0.5 \Omega \times 1.1$ and $L=4.6 \mathrm{mH} \times 0.9$ (a) in the rectifier mode with the average power $\approx 530 \mathrm{~W}$ (i.e., $I_{\mathrm{cc}}=0 \mathrm{~A}$ ), (b) in the inverter mode with the average power $\approx-470 \mathrm{~W}$ (i.e,. $I_{\mathrm{cc}}=5 \mathrm{~A}$ ).

waveforms at the rectifier mode and the inverter mode are plotted in Fig. 12(a) and (b), respectively.

The results show that the proposed BCSC is stable, but the circuit yields larger current harmonics than the uncertainty-free case as shown in Fig. 10. However, the current waveforms in Fig. 12 are better than the special case with considering only inductance as shown in Fig. 11, which also shows the benefits of considering the resistance and the conduction voltage in this paper.

The simulated waveforms with the average power $\approx 320 \mathrm{~W}$ (i.e., $I_{\mathrm{cc}}=1.0 \mathrm{~A}$ ) and input voltage 90 Vrms are plotted in Fig. 13(a). Additionally, the simulated waveforms with the average power $\approx-750 \mathrm{~W}$ (i.e., $I_{\mathrm{cc}}=6.5 \mathrm{~A}$ ) under input voltage 130 Vrms are plotted in Fig. 13(b).

The yielded currents initiate flowing at the voltage ZCPs, and returns to zero near the next ZCPs, which shows that the proposed BCSC is able to work under various power levels and various input voltages. However, the reported total harmonic distortion (THD) value in Fig. 13 is smaller than the uncertaintyfree case as shown in Fig. 10. It means that the circuit parameters need to be optimized to yield the smallest current harmonics at the rated conditions.

\section{Transient Response}

In order to evaluate the transient performance of the proposed $\mathrm{BCSC}$, the simulated waveform with the sudden change of dc current source from $I_{\mathrm{cc}}=0 \mathrm{~A}$ to $I_{\mathrm{cc}}=4 \mathrm{~A}$ and from $I_{\mathrm{cc}}=4 \mathrm{~A}$ to $I_{\mathrm{cc}}=0 \mathrm{~A}$ are plotted in Fig. 14(a) and (b), respectively.

In Fig. 11(a), the current $I_{\mathrm{cc}}$ increases suddenly from 0 to $4 \mathrm{~A}$, and the dc-side current $I_{\mathrm{dc}}$ has a sudden drop from 2 to $-2 \mathrm{~A}$. The sudden change contributes to the rapid rise of the dc-bus

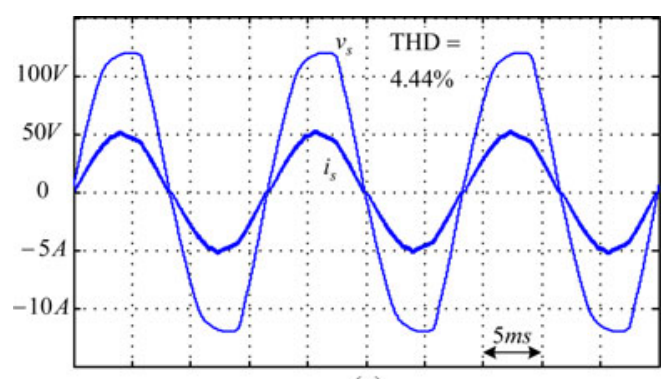

(a)

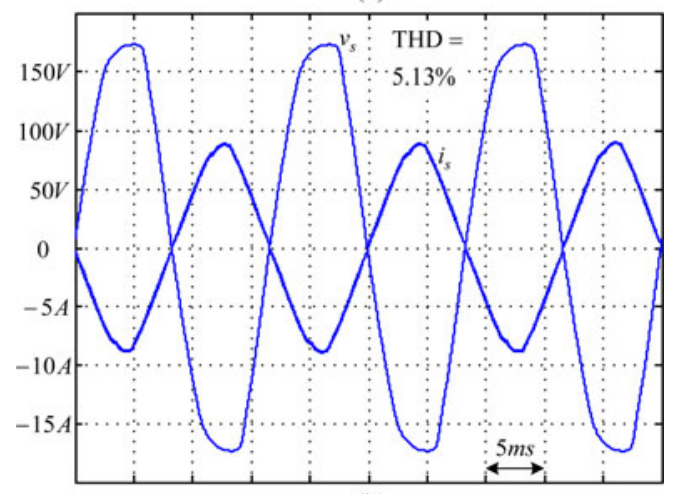

(b)

Fig. 13. Simulation results with various power levels and various input voltages (a) with the average power $\approx 320 \mathrm{~W}$ (i.e., $I_{\mathrm{cc}}=1.0 \mathrm{~A}$ ) under input voltage $90 \mathrm{Vrms}$, (b) with the average power $\approx-750 \mathrm{~W}$ (i.e,. $I_{\mathrm{cc}}=6.5 \mathrm{~A}$ ) under input voltage 130 Vrms.

voltage $V_{o}$. It means that the full-bridge ac/dc converter needs to operate at the inverter mode to sweep the power imbalance.

At the same time, the negative voltage error $\varepsilon_{V}$ turns to negative, and thus, the PI-type controller tunes its output $\hat{V}_{L}$ from the positive value $9.2 \mathrm{~V}$ to the negative value $-7.9 \mathrm{~V}$ in order to regulate the dc-bus voltage $V_{o}$. After less than $40 \mathrm{~ms}$, the dc-bus voltage is restored and the yielded input current is near sinusoidal waveform.

Due to the input inductance in the ac grid, the measured voltage $v_{s}$ in the rectifier operation is the infinite bus voltage minus the voltage drop of the inductor. But in the inverter operation, the voltage drop is negative and the ac-grid voltage $v_{s}$ would be larger than that in the rectifier operation. Therefore, the peak amplitude of the ac-side voltage $v_{s}$ increases as shown in Fig. 14(a) after the full-bridge converter changes from the rectifier mode to the inverter mode.

Similarly, when the current $I_{\text {cc }}$ decreases suddenly from 4 to $0 \mathrm{~A}$, the dc-bus voltage $V_{o}$ drops rapidly. In order to regulate the dc-bus voltage, the full-bridge converter needs to operate at rectifier mode and thus, the peak amplitude of the ac-side voltage decreases as shown in Fig. 14(b).

Therefore, the provided simulation results demonstrate the proposed BCSC.

\section{EXPERIMENTAL RESULTS}

The experimental setup and the FPGA-based implementation of the proposed BCSC are plotted in Fig. 15. The circuit parameters had been tabulated in Table II. A dc power source operating 


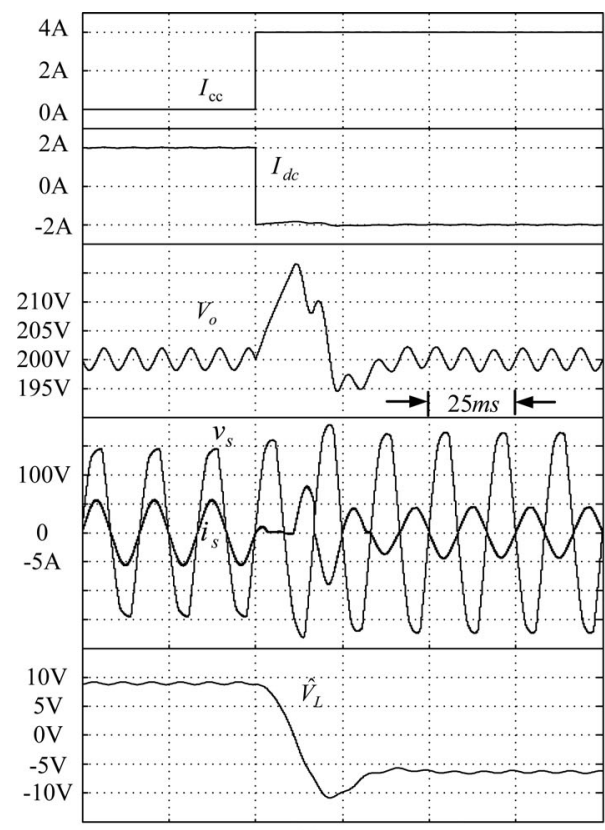

(a)

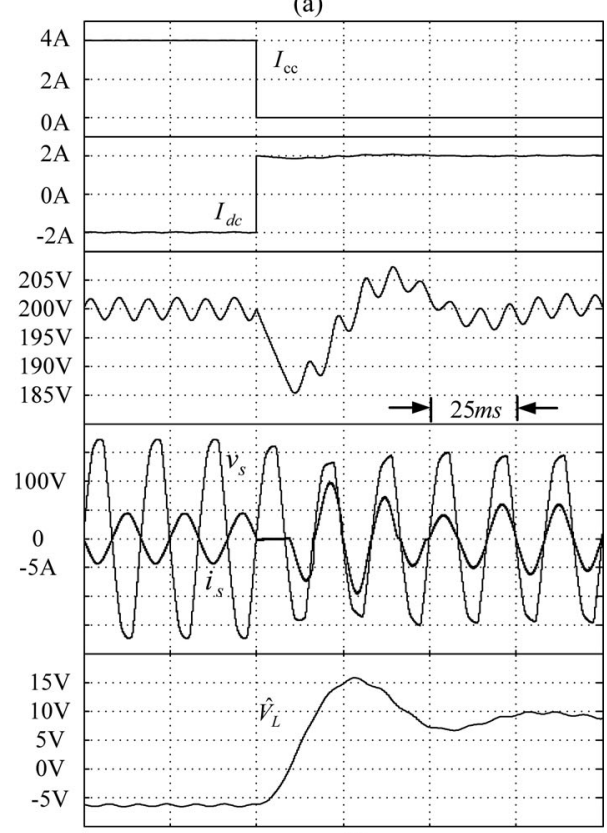

(b)

Fig. 14. Simulation results when dc current source suddenly changes (a) from $I_{\mathrm{cc}}=0 \mathrm{~A}$ to $I_{\mathrm{cc}}=4 \mathrm{~A}$, (b) from $I_{\mathrm{cc}}=4 \mathrm{~A}$ to $I_{\mathrm{cc}}=0 \mathrm{~A}$.

at $\mathrm{CC}$ mode is connected to the dc bus to represent the direct power flow into the dc bus.

Due to no A/D function in a commercial FPGA chip, an external $\mathrm{A} / \mathrm{D}$ converter is used to sense the output voltage and a zero-crossing detecting circuit is used to detect the zero-crossing of the ac-side voltage. Some D/A converters are used to show the control variables of the implemented BCSC in the scope.

The average current model is the basis of the proposed BCSC and it is developed based on the CCM assumption. When the input ac voltage is at near ZCPs, the circuit often operates in DCM due to the cusp distortion. To meet the assumption of

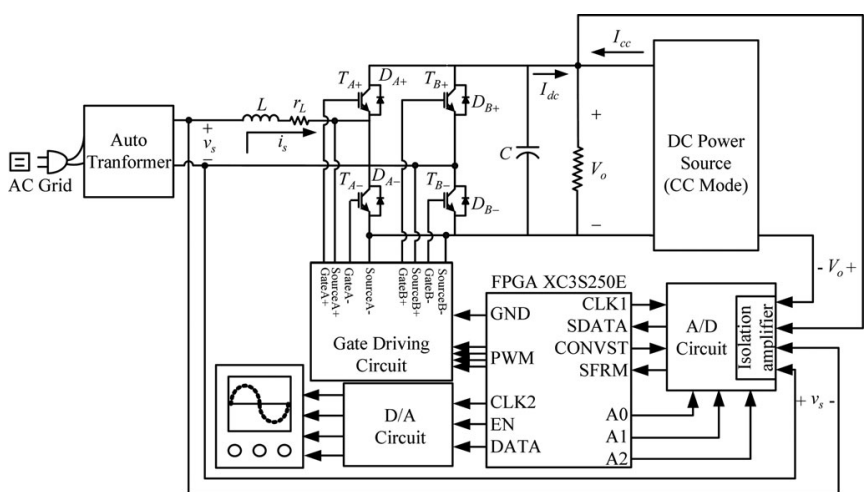

Fig. 15. Experimental setup of the proposed BCSC.

CCM, either high switching frequency or the bulky inductor should be selected.

The switching frequency $40 \mathrm{kHz}$ is first selected based on the concern of PWM resolution in the FPGA-based implementation. Therefore, the bulky inductor $4.6 \mathrm{mH}$ is selected to guarantee the CCM assumption. Those current sensorless control methods in Table I also select bulky inductors.

\section{A. Pure Sinusoidal Grid Voltage}

In order to provide a pure sinusoidal voltage waveform, an equipment (named programmable ac voltage source) is directly connected to the ac-side voltage. The current $I_{\mathrm{cc}}$ is set to zero and thus, the full-bridge converter needs to operate at rectifier mode. The yielded ac-side current and the dc-bus voltage waveform is plotted in Fig. 16(a).

Because that the programmable ac power source cannot absorb power, no experimental result of the inverter mode with the sinusoidal voltage is provided.

\section{B. Distorted Grid Voltage}

By plugging into the ac grid, the yielded waveforms at rectifier mode and at inverter mode are plotted in Fig. 16(b) and (c), respectively. In Fig. 16(b), the current $I_{\mathrm{cc}}$ in dc power source is set to zero and the full-bridge converter needs to operate in rectifier mode to regulate the dc-bus voltage. The yielded input current $i_{s}$ is in phase with the input voltage, and some distortion can be found in Fig. 16(b) due to the distorted grid voltage. The measured THD factor is $4.81 \%$.

In Fig. 16(c), the current $I_{\mathrm{cc}}$ in dc power source is set to $5 \mathrm{~A}$ and the full-bridge converter needs to transfer some power to ac grid to balance the power. The yielded input current $i_{s}$ is aligned to the ac-side voltage $v_{s}$, and the measured THD factor is $14.84 \%$.

Due to the voltage drop across the input inductance as shown in Fig. 2, the peak amplitude of the measured ac-side voltage $v_{s}$ at Fig. 16(c) is larger than that in Fig. 16(b).

Since the dc power supply is operated in CC mode, its output current $I_{\mathrm{cc}}$ may be disturbed by the variation of the dc-bus voltage. Therefore, as shown in Fig. 14, the current $I_{\mathrm{cc}}$ carries double line-frequency ripple due to the double line-frequency voltage ripple in the dc voltage $V_{o}$. Thus, when the converter 




(a)

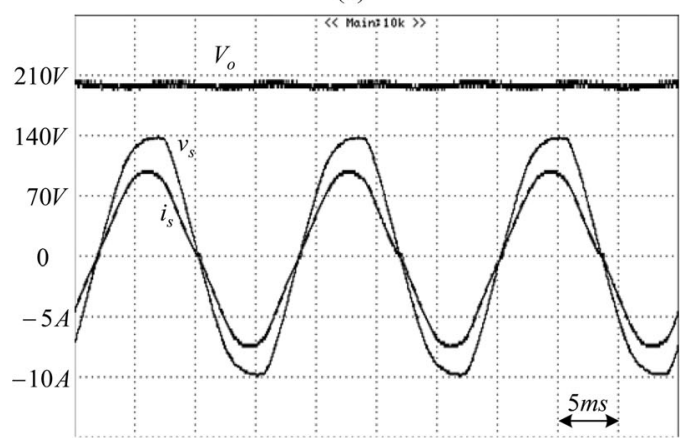

(b)

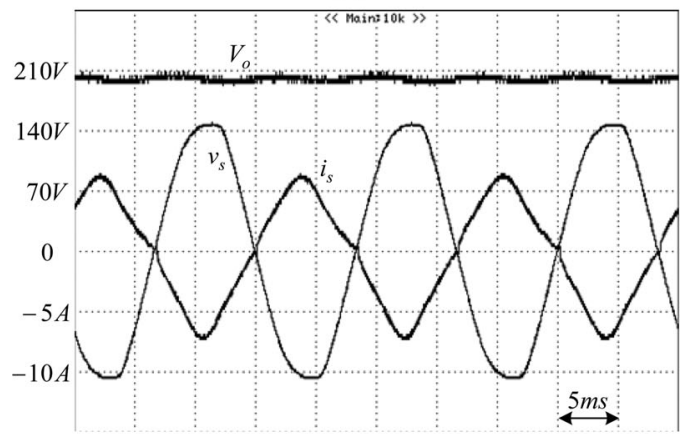

(c)

Fig. 16. Experimental waveforms (a) with sinusoidal input voltage (average input power $\approx 500 \mathrm{~W}$ ); (b) with distorted input voltage (average input power $\approx 500 \mathrm{~W}$ ); (c) with distorted input voltage (average input power $\approx-500 \mathrm{~W}$ ).

operated in inverter operation, the current $I_{\mathrm{cc}}$ does not keep fixed.

But the current $I_{\mathrm{cc}}$ has no current ripple when the current $I_{\mathrm{cc}}$ is set to zero. Therefore, the yielded current waveform of the inverter operation as shown in Fig. 16(c) possesses larger harmonics than that as shown in Fig. 16(b).

The experimental waveforms at distorted input voltages 90 Vrms and 130 Vrms are plotted in Figs. 17 and 18, respectively. The results show that the proposed BCSC is able to work under various input voltage and various power levels.

\section{Transient Response}

The experimental results during the change of power supply current $I_{\mathrm{cc}}$ from 0 to $4 \mathrm{~A}$ and from 4 to $0 \mathrm{~A}$ are plotted in Fig. 19(a) and (b), respectively. The dc-bus voltage $V_{o}$ is well regulated to $200 \mathrm{~V}$ and the yielded input current $i_{s}$ is in phase with the input voltage. Like the simulation results in Fig. 14, the



(a)

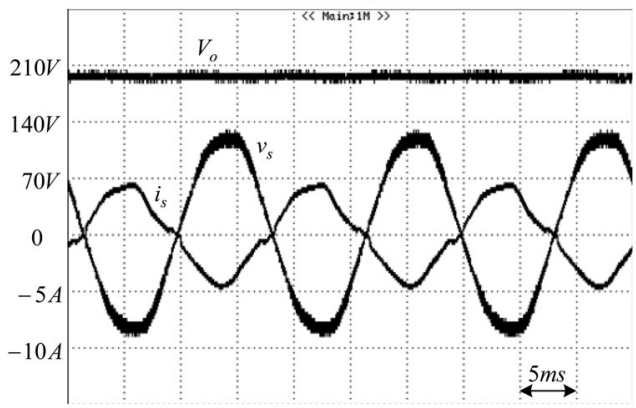

(b)

Fig. 17. Experimental waveforms at distorted input voltage 90 Vrms (a) with average input power $\approx 300 \mathrm{~W}$; (b) with average input power $\approx-300 \mathrm{~W}$.

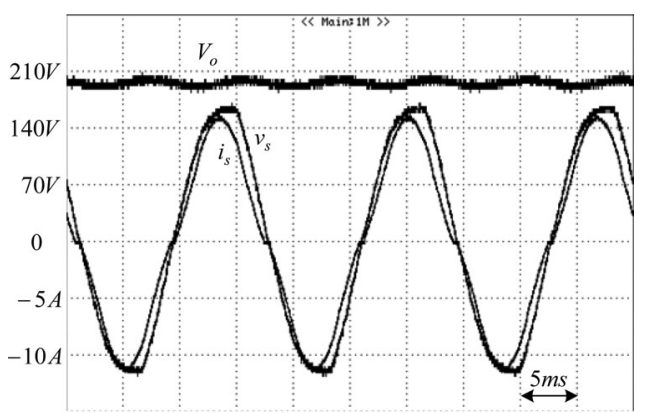

(a)

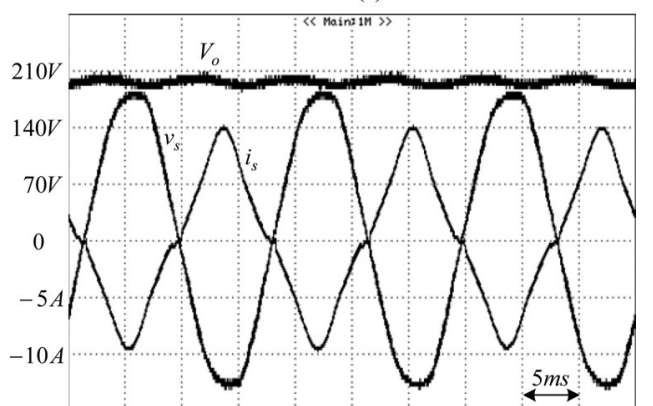

(b)

Fig. 18. Experimental waveforms at distorted input voltage $130 \mathrm{Vrms}$ (a) with average input power $\approx 800 \mathrm{~W}$; (b) with average input power $\approx-800 \mathrm{~W}$.

peak amplitude of the ac-side voltage $v_{s}$ may changes after the operation mode of the full-bridge converter is changed.

In addition, the real power supply current $I_{\mathrm{cc}}$ cannot change suddenly like the simulations in Fig. 14, and it has a significant transient time near $20 \mathrm{~ms}$. In fact, the direct power flow to the dc 


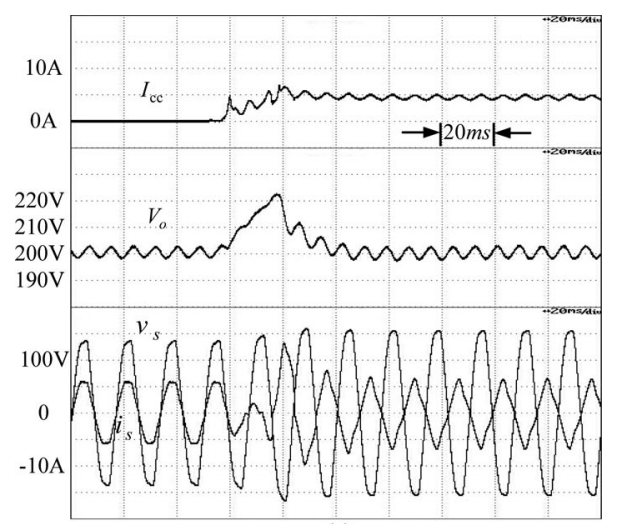

(a)

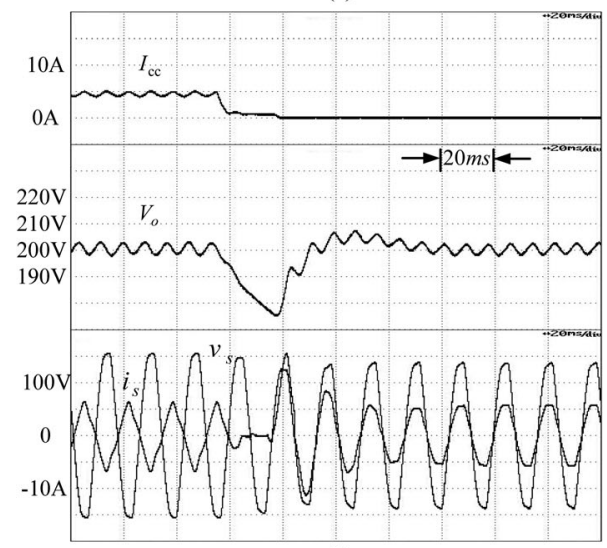

(b)

Fig. 19. Experimental waveforms during the change of direct dc power flow (a) from $I_{\mathrm{cc}}=0 \mathrm{~A}$ to $I_{\mathrm{cc}}=4 \mathrm{~A}$, (b) from $I_{\mathrm{cc}}=4 \mathrm{~A}$ to $I_{\mathrm{cc}}=0 \mathrm{~A}$.

bus cannot change suddenly and thus, the transient time makes the experiment more closed to the practical condition.

However, these results have verified the feasibility of the proposed system and control scheme.

\section{CONCLUSION}

In this paper, the behavior of the full-bridge ac/dc converter has been studied and its single-switch model is proposed. According to the developed equivalent single-switch model, BCSC has been proposed and implemented. The experiment results show that the proposed BCSC is able to shape the ac-side current and regulate the dc-side voltage. The proposed BCSC with reduced number of sensor can be used to regulate the dc-grid voltage in the household application. However, the waveform in the inverter operation has larger current harmonic than that in the rectifier operation, which needs more attention to improve it.

\section{REFERENCES}

[1] J. C. Salmon, "Circuit topologies for single-phase voltage-doubler boost rectifiers," IEEE Trans. Power Electron., vol. 8, no. 5, pp. 521-529, Oct. 1993.

[2] B. Singh, B. N. Singh, A. Chandra, K. Al-Haddad, A. Pandey, and D. P. Kothari, "A review of single-phase improved power quality ACDC converters," IEEE Trans. Ind. Electron., vol. 50, no. 5, pp. 962-981, Oct. 2003.
[3] E. Cipriano, C. B. Jacobina, E. R. C. da Silva, and N. Rocha, "SingePhase to three-phase power converters: State of the art," IEEE Trans. Power Electron., vol. 27, no. 5, pp. 2437-2452, May 2012.

[4] Y. K. Lo, "Dual hysteresis loops for a high-performance four-switch boost rectifier," IEEE Trans. Ind. Electron., vol. 47, no. 5, pp. 1174-1176, Oct. 2000.

[5] R. Wang, F. Wang, D. Boroyevich, R. Burgos, R. Lai, P. Ning, and K. Rajashekara, "A high power density single-phase PWM rectifier with active ripple energy storage," IEEE Trans. Power Electron., vol. 26, no. 5, pp. 1430-1443, May 2011.

[6] C. B. Jacobina, E. C. Edos Santos, N. Rocha, and E. L. Lopes Fabricio, "Single-Phase to three-phase drive system using two parallel single-phase rectifiers," IEEE Trans. Power Electron., vol. 25, no. 5, pp. 1285-1295, May 2010.

[7] C. B. Jacobina, E. C. Edos Santos, N. Rocha, B. D. S. Gouveia, and E. da Silva, "Reversible AC drive systems based on parallel AC-AC DCLink converters," IEEE Trans. Ind. Appl., vol. 46, no. 4, pp. 1456-1467, Jul./Aug. 2010.

[8] C. Meza, J. J. Negroni, D. Biel, and F. Guinjoan, "Energy-Balance modeling and discrete control for single-phase grid connected PV central inverters," IEEE Trans. Ind. Electron., vol. 55, no. 7, pp. 2734-2743, Jul. 2008.

[9] B. Yang, Y. Zhao, and X. He, "Design and analysis of a grid-connected photovoltaic power system," IEEE Trans. Power Electron., vol. 25, no. 4 pp. 992-1000, Apr. 2010.

[10] L. Zhang, K. Sun, Y. Xing, L. Feng, and H. Ge, "A modular grid-connected photovoltaic generation system based on DC bus," IEEE Trans. Power Electron., vol. 26, no. 2, pp. 523-531, Feb. 2011.

[11] Y. H. Liao and C. M. Lai, "Newly-Constructed simplified single-phase multistring multilevel inverter topology for distributed energy resources," IEEE Trans. Power Electron., vol. 26, no. 9, pp. 2386-2392, Sep. 2011.

[12] M. Pascual, G. Garcera, E. Figueres, and F. Gonzalez-Espin, "Robust model-following control of parallel UPS single-phase inverters," IEEE Trans. Ind. Electron., vol. 55, no. 8, pp. 2870-2883, Aug. 2008.

[13] Y. C. Chang and C. M. Liaw, "Establishment of a switched-reluctance generator-based common microgrid system," IEEE Trans. Power Electron., vol. 26, no. 9, pp. 2512-2527, Sep. 2011.

[14] T. F. Wu, K. H. Sun, C. L. Kuo, and C. H. Chang, "Predictive current controlled 5-kW single-phase bidirectional inverter with wide inductance variation for DC-Microgrid applications," IEEE Trans. Power Electron., vol. 25, no. 12, pp. 3076-3084, Dec. 2010.

[15] S. C. Yip, D. Y. Qiu, H. S. H. Chung, and S. Y. R. Hui, "A novel voltage sensorless control technique for a bidirectional AC/DC converter," IEEE Trans. Power Electron., vol. 18, no. 6, pp. 1346-1355, Nov 2003.

[16] H. M. Kojabadi, B. Yu, I. A. Gadoura, L. Chang, and M. Ghribi, "A novel DSP-based current-controlled PWM strategy for single phase grid connected inverters," IEEE Trans. Power Electron., vol. 21, no. 4, pp. 985 993, Jul. 2006.

[17] M. Rodriguez, V. M. Lopez, F. J. Azcondo, J. Sebastian, and D. Maksimovic, "Average inductor current sensor for digitally controlled switched-mode power supplies," IEEE Trans. Power Electron., vol. 27, no. 8, pp. 3795-4029, Aug. 2012.

[18] K. I. Hwu, H. W. Chen, and Y. T. Yau, "Fully digitalized implementation of PFC rectifier in CCM without ADC," IEEE Trans. Power Electron., vol. 27, no. 9, pp. 4021-4029, Sep. 2012.

[19] S. Sivakumar, K. Natarajan, and R. Gudelewicz, "Control of power factor correcting boost converter without instantaneous measurement of input current," IEEE Trans. Power Electron., vol. 10, no. 4, pp. 435-445, Jul. 1995.

[20] Y. L. Lo, H. J. Chiu, and S. Y. Ou, "Constant-Switching-Frequency control of switch-mode rectifiers without current sensors," IEEE Trans. Ind. Electron., vol. 47, no. 5, pp. 1172-1147, Oct. 2000.

[21] W. Zhang, G. Feng, Y. F. Liu, and B. Wu, "A digital power factor correction (PFC) control strategy optimized for DSP," IEEE Trans. Power Electron., vol. 19, no. 6, pp. 1474-1485, Nov. 2004.

[22] H. C. Chen, "Single-Loop current sensorless control for single-phase boost-type SMR," IEEE Trans. Power Electron., vol. 24, no. 1, pp. 163 171, Jan. 2009

[23] F. J. Azcondo, A. Castro, V. M. Lopez, and O. Garica, "Power factor correction without current sensor based on digital current rebuilding," IEEE Trans. Power Electron., vol. 25, no. 6, pp. 1527-1536, Jun. 2010. 


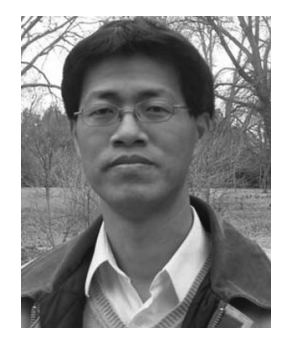

Hung Chi Chen (M'06) was born in Taichung, Taiwan, in June 1974. He received the B.S. and Ph.D. degrees from the Department of Electrical Engineering, National Tsing-Hua University, Hsinchu, Taiwan, in June 1996 and June 2001, respectively.

From October 2001, he was a Researcher at the Energy and Resources Laboratory, Industrial Technology Research Institute ITRI, Hsinchu. In August 2006, he joined the Department of Electrical and Control, National Chiao-Tung University, Hsinchu, where he is currently an Associate Professor. From September 2011 to February 2012, he was a Visiting Scholar in the University of Texas in Arlington. His research interests include power electronics, power factor correction, motor and inverter-fed control, DSP/MCU/FPGA-based implementation of digital control.

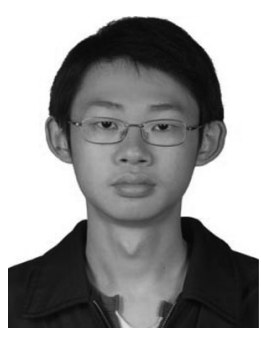

Jhen Yu Liao was born in Taoyuan, Taiwan, in August 1986. He received the B.S. degrees from the Department of Mechatronic Technology, National Taiwan Normal University, Taipei, Taiwan, in June 2008, and the M.S. degree from the Institute of Electrical Control Engineering, National Chiao Tung University, Hsinchu, Taiwan, in June 2010. He is currently working toward the Ph.D. degree in National Chiao Tung University.

His research interests include power electronics based implementation of digital control. 